\title{
Clinical utility of a screening protocol for blunt cerebrovascular injury using computed tomography angiography
}

\author{
Michael K. Tso, MD, ${ }^{1}$ Myunghyun M. Lee, MD, ${ }^{2}$ Chad G. Ball, MD, ${ }^{3}$ William F. Morrish, MD, ${ }^{4}$ \\ Alim P. Mitha, MD, SM, ${ }^{1,4}$ Andrew W. Kirkpatrick, MD, MHSc, ${ }^{3}$ and John H. Wong, MD, MSc ${ }^{1,4}$ \\ 1Division of Neurosurgery, Department of Clinical Neurosciences, ${ }^{3}$ Department of Surgery, and ${ }^{4}$ Division of Neuroradiology, \\ Department of Diagnostic Imaging, University of Calgary, Foothills Medical Centre, Calgary, Alberta; and 2Division of Cardiac \\ Surgery, University of Toronto, Ontario, Canada
}

\begin{abstract}
OBJECTIVE Blunt cerebrovascular injury (BCVI) occurs in approximately $1 \%$ of the blunt trauma population and may lead to stroke and death. Early vascular imaging in asymptomatic patients at high risk of having BCVI may lead to earlier diagnosis and possible stroke prevention. The objective of this study was to determine if the implementation of a formalized asymptomatic BCVI screening protocol with CT angiography (CTA) would lead to improved BCVI detection and stroke prevention.

METHODS Patients with vascular imaging studies were identified from a prospective trauma registry at a single Level 1 trauma center between 2002 and 2008. Detection of BCVI and stroke rates were compared during the 3-year periods before and after implementation of a consensus-based asymptomatic BCVI screening protocol using CTA in 2005.

RESULTS A total of 5480 patients with trauma were identified. The overall BCVI detection rate remained unchanged postprotocol compared with preprotocol ( $0.8 \%$ [24 of 3049 patients] vs $0.9 \%$ [23 of 2431 patients]; $p=0.53$ ). However, postprotocol there was a trend toward a decreased risk of stroke secondary to $\mathrm{BCVI}$ on a trauma population basis ( $0.23 \%$ [ 7 of 3049 patients] vs $0.53 \%$ [13 of 2431 patients]; $p=0.06$ ). Overall, $75 \%$ (35 of 47 ) of patients with BCVI were treated with antiplatelet agents, but no patient developed new or progressive intracranial hemorrhage despite $70 \%$ of these patients having concomitant traumatic brain injury.
\end{abstract}

CONCLUSIONS The results of this study suggest that a CTA screening protocol for BCVI may be of clinical benefit with possible reduction in ischemic complications. The treatment of BCVI with antiplatelet agents appears to be safe.

https://thejns.org/doi/abs/10.3171/2016.1.JNS151545

KEY WORDS blunt cerebrovascular injury; stroke; trauma; computed tomography angiography; screening

$\mathrm{B}$ LUNT cerebrovascular injury (BCVI) is characterized by trauma to the vascular wall of the carotid and vertebral arteries. This vascular trauma has a wide spectrum of manifestations, ranging from subtle intimal injury to complete arterial transection. The first large case series of BCVI was published in 1996 by Fabian et al. ${ }^{15}$ Since then, there has been a growing awareness to screen for BCVI in trauma centers. The occurrence of $\mathrm{BCVI}$ in patients with blunt trauma can range from $0.1 \%$ in an institution that does not routinely screen for BCVI to $2.7 \%$ in an institution that does have a screening protocol in place. ${ }^{7}$ Blunt cerebrovascular injury may lead to ischemic stroke in a delayed manner, which has a morbidity and mortality of up to $80 \%$ and $40 \%$, respectively. ${ }^{7}$ Hence, early detection of BCVI with vascular imaging may allow an opportunity to prevent ischemic complications.

Although digital subtraction angiography (DSA) remains the gold standard in detecting BCVI, ${ }^{12}$ screening using CT angiography (CTA) has been used in many clinical centers for the following reasons: 1) it is less invasive than DSA; 2) there are no catheter-related complications such as iatrogenic ischemic stroke; 3 ) less iodine-based contrast may be required compared with DSA, which may reduce the risk of contrast-associated acute kidney injury; 4) most patients with blunt trauma are already undergoing CT scans of other body regions-thus additional transporta-

ABBREVIATIONS ASA = acetylsalicylic acid; BCVI = blunt cerebrovascular injury; $C T A=C T$ angiography; $D S A=$ digital subtraction angiography; $\mathrm{GCS}=$ Glasgow Coma Scale; ISS = injury severity score; LOS = length of stay; MRA = MR angiography; $\mathrm{mRS}=$ modified Rankin Scale.

SUBMITTED July 2, 2015. ACCEPTED January 27, 2016.

INCLUDE WHEN CITING Published online April 22, 2016; DOI: 10.3171/2016.1.JNS151545. 
tion of critically ill patients to the angiography suite is not required; and 5) it is less personnel and resource intensive. Also, patients with BCVI that is diagnosed based on DSA but is not detected on CTA may have a more favorable prognosis. $^{2}$

The Western Trauma Association and Eastern Trauma Association have published clinical guidelines and evidence-based reviews of screening and treatment strategies for BCVI in patients with trauma. ${ }^{1,7}$ These guidelines recommend the creation of an institutional BCVI screening protocol at all trauma centers. Biffl et al. have previously demonstrated improved BCVI diagnosis and decreased stroke rate after establishing a BCVI screening protocol with DSA, during a time when BCVI awareness was not widespread in trauma centers. ${ }^{6}$ Some have advocated the need for studies demonstrating the clinical impact of CTA screening protocols for BCVI. ${ }^{21}$ The objective of this study was to investigate the utility of a consensus-based BCVI screening protocol with CTA at a single Level 1 trauma center. We examined the rates of BCVI detection and ischemic complications before and after implementation of a BCVI screening protocol.

\section{Methods}

This study received approval from our institutional Conjoint Health Research Ethics Board.

\section{Development of the BCVI Screening Protocol}

An institutional screening protocol for asymptomatic BCVI with CTA was developed and implemented in August 2005 at Foothills Medical Centre by the Adult Trauma Quality Assessment Management Committee with input from multiple specialties including trauma surgery, radiology, neurosurgery, stroke neurology, and critical care medicine. Before the development of this protocol, the use of CTA to screen for asymptomatic BCVI was less systematic and was at the discretion of the Trauma Team Leader.

Our screening protocol is a modification of the Denver screening criteria, which include: 1) severe injury mechanism involving severe cervical hyperextension/rotation or hyperflexion associated with displaced midface, complex mandibular fracture, or closed head injury with diffuse axonal injury; 2) near hanging resulting in anoxic brain injury; 3) physical signs including seat belt abrasion across the neck or neck swelling; 4) basal skull fracture involving the carotid canal; and 5) cervical spine fracture involving the vertebral body in a previously normal spine (not degenerative or pathological) or involving the transverse foramen. ${ }^{5}$

If a patient with trauma satisfies at least 1 of the screening criteria, then CTA of the head and neck is obtained within the next 24 hours, if feasible. Patients with suspected symptomatic BCVI (e.g., cervical bruit in a patient younger than 50 years old, hemiparesis or other lateralizing signs, neurological symptoms or deficits not explained by radiological imaging, persistent epistaxis or bleeding from the ears, or ischemic infarct on neurological imaging not otherwise explained from initial injury) undergo CTA regardless of whether screening criteria are present.

\section{Patient Population}

Foothills Medical Centre is one of the largest hospitals in Canada. It is the sole accredited Level 1 trauma center for more than 2 million people living in a catchment area that includes the southern half of the province of $\mathrm{Al}-$ berta, as well as parts of neighboring provinces of British Columbia and Saskatchewan. Patients with trauma were identified using a prospective hospital trauma registry (Alberta Trauma Registry), which contains clinical information of all patients with trauma presenting to Foothills Medical Centre with an injury severity score (ISS) of at least 12 . The time frame of our study was divided into two 3-year periods-August 2002 to July 2005 (during which time 2431 patients were identified) and August 2005 to July 2008 (3049 patients were identified)-representing time periods before and after implementation of the BCVI screening protocol, respectively. Clinical data, including demographic information, BCVI risk factors, and injury profile, were obtained via retrospective analysis of the prospectively collected database. Patients with penetrating vascular injuries were excluded.

\section{Imaging Protocol}

From 2002 to 2005, a 4-channel multidetector CT scanner (General Electric) was used. A 40-channel multidetector CT scanner (Siemens) was used briefly from 2005 to 2006, followed by a 64-channel multidetector CT scanner (Siemens) from 2006 to 2008. From the database, all vascular imaging reports for patients with trauma who were admitted during the time period of interest were reviewed. Imaging modalities included CTA, MR angiography (MRA), and DSA. If there were any discrepancies between imaging reports from different modalities, then any reported DSA results were considered the gold standard. Similarly, CTA was considered more reliable than MRA.

The imaging results of patients diagnosed with BCVI were analyzed and classified based on the Denver grading scale: Grade 1, intimal irregularity or dissection causing < $25 \%$ luminal narrowing; Grade 2, dissection, raised flap, or thrombus causing $>25 \%$ luminal narrowing; Grade 3, pseudoaneurysm; Grade 4, occlusion; and Grade 5, transection. ${ }^{4}$ Traumatic carotid-cavernous fistula was treated as a separate entity due to its distinct clinical course compared with other Grade 5 vascular injuries. Vascular imaging studies of patients with trauma who were not reported to have BCVI were not reanalyzed. The BCVI detection rate was calculated by dividing the number of patients positively diagnosed with BCVI by the total number of patients with trauma in the database for that time period.

\section{Stroke, Hospital Course, and Clinical Outcomes}

Ischemic stroke was diagnosed based on retrospective analysis of inpatient charts, review of the complications data from the Alberta Trauma Registry, and review of neuroimaging reports. We defined stroke as a new neurological deficit not otherwise explained by the existing injuries and supported by radiological imaging. The BCVI stroke rate was calculated by dividing the number of patients with BCVI who had ischemic complications by the total number of patients with trauma in the database for 
that time period. Data concerning hospital length of stay (LOS) and mortality were also collected from the registry. Clinical outcomes at hospital discharge were based on the modified Rankin Scale (mRS). The mRS scores range from 0 to 6 , with 0 meaning the patient is asymptomatic and 6 indicating death.

\section{Statistical Analysis}

Descriptive statistics are reported as the means and/or medians with SDs. Baseline demographic data and clinical information pre- versus postprotocol were compared using the chi-square test or Fisher's exact test for categorical data and dichotomous data, respectively, and 2-tailed Student's t-test for continuous data. The BCVI detection rate and stroke rate were compared before and after protocol implementation using Fisher's exact test. The mRS scores at hospital discharge and the time to vascular imaging or treatment were compared before and after protocol implementation using the Mann-Whitney U-test. A p value $<0.05$ was considered significant. A p value between 0.05 and 0.10 was considered a statistical trend. Statistical tests were performed using Stata 12.0 (StataCorp).

\section{Results}

\section{Trauma Registry Population Characteristics}

Clinical information and frequencies of various BCVI risk factors are shown in Table 1 for the overall trauma population. Postprotocol, the patients were slightly older (46.3 years vs 43.8 years; $p<0.001$ ) and were less likely to be intubated ( $16.4 \%$ vs $18.9 \%$; $p=0.01)$. Otherwise, there were no significant differences in clinical data and fre- quencies of various BCVI risk factors pre- versus postprotocol.

\section{Vascular Imaging in Patients With Trauma}

Data regarding the use of vascular imaging in patients with trauma are presented in Table 2. Preprotocol, patients with trauma underwent significantly more MRA and DSA studies than postprotocol. After protocol implementation, patients with trauma underwent significantly more CTA studies and vascular imaging studies in general. Overall, among patients with trauma who had BCVI risk factors, there were more missed BCVI screenings before compared with after protocol implementation (51\% [133 of 260 ] vs $20 \%$ [60 of 306]; $p<0.001$ ).

\section{Diagnosis of BCVI in Patients With Trauma}

There was no significant difference in the proportion of patients with trauma diagnosed with BCVI before compared with after protocol implementation (0.9\% [23 of 2431] vs $0.8 \%$ [24 of 3049]; $\mathrm{p}=0.53$; Table 3). The mean number of days after initial presentation with trauma before being diagnosed with BCVI on vascular imaging was 8.2 (median 3 ) days and 2.5 (median 1 ) days pre- and postprotocol, respectively $(\mathrm{p}=0.12)$. Overall, $4 \%$ ( 2 of 47$)$ of these patients had $>1$ vascular territory affected, and both of these patients were identified postprotocol. Although not included in our BCVI series analysis, there were 2 patients with traumatic carotid-cavernous fistulas preprotocol, and none were identified postprotocol.

There was also no significant difference in baseline clinical information of patients with trauma who had BCVI

TABLE 1. Clinical information and frequency of BCVI risk factors in patients with trauma pre- and postprotocol

\begin{tabular}{|c|c|c|c|}
\hline Variable & $\begin{array}{l}\text { Preprotocol, 2002-2005, } \\
\qquad n=2431\end{array}$ & $\begin{array}{l}\text { Postprotocol, 2005-2008, } \\
\qquad \mathrm{n}=3049\end{array}$ & $\mathrm{p}$ Value \\
\hline Age in yrs, mean $\pm S D$ & $43.8 \pm 20.7$ & $46.3 \pm 21.4$ & $<0.001^{*}$ \\
\hline Sex, F; no. (\%) & $670(28)$ & $799(26)$ & 0.26 \\
\hline ISS, mean \pm SD & $22.7 \pm 9.3$ & $22.6 \pm 8.8$ & 0.78 \\
\hline GCS score at presentation to trauma center, mean \pm SD & $14.1 \pm 2.4$ & $14.0 \pm 2.5$ & 0.19 \\
\hline In-hospital mortality, no. (\%) & $239(9.8)$ & $312(10.2)$ & 0.62 \\
\hline Hospital LOS in days, mean \pm SD & $13.6 \pm 18.6$ & $13.5 \pm 19.3$ & 0.86 \\
\hline Intubated at hospital presentation, no. (\%) & $460(18.9)$ & $500(16.4)$ & $0.01^{*}$ \\
\hline \multicolumn{4}{|l|}{$\mathrm{BCVI}$ risk factors, no. of pts } \\
\hline Displaced midface & 3 & 2 & 0.66 \\
\hline Complex mandibular Fx & 35 & 52 & 0.43 \\
\hline Closed head injury w/ DAl & 74 & 83 & 0.48 \\
\hline Near hanging & 1 & 0 & 0.44 \\
\hline Physical signs $†$ & 7 & 15 & 0.24 \\
\hline Fx involving carotid canal & 12 & 17 & 0.75 \\
\hline Fx involving transverse foramen & 32 & 37 & 0.73 \\
\hline Cervical vertebral body Fx & 132 & 145 & 0.26 \\
\hline At least $1 \mathrm{BCVI}$ risk factor, no. (\%) & $260(10.7)$ & $306(10.0)$ & 0.43 \\
\hline$>1$ BCVI risk factor, no. (\%) & $63(2.6)$ & $71(2.3)$ & 0.53 \\
\hline
\end{tabular}


TABLE 2. Use of vascular imaging in patients with trauma pre- and postprotocol

\begin{tabular}{lrrr}
\hline & Imaging Modality & Preprotocol, 2002- & Postprotocol, 2005- \\
& $2005, \mathrm{n}=2431$ & $2008, \mathrm{n}=3049$ & $\mathrm{p} \mathrm{Value}$ \\
\hline No. of pts w/ CTA & $80(3.3 \%)$ & $239(7.8 \%)$ & $<0.001^{*}$ \\
\hline No. of pts w/ MRA & $42(1.7 \%)$ & $2(0.1 \%)$ & $<0.001^{*}$ \\
\hline No. of pts w/ DSA & $14(0.6 \%)$ & $7(0.2 \%)$ & $0.039^{*}$ \\
\hline No. of pts w/ any vascular imaging & $121(5.0 \%)$ & $244(8.0 \%)$ & $<0.001^{*}$ \\
\hline No. of pts w/ >1 vascular imaging modality & $13(0.5 \%)$ & $3(0.1 \%)$ & $0.003^{*}$ \\
\hline $\begin{array}{l}\text { No. of pts w/ BCVI risk factor(s) but not undergoing vascular imag- } \\
\text { ing (expressed as proportion of those with BCVI risk factor[s]) }\end{array}$ & $133: 260(51.2 \%)$ & $60: 306(19.6 \%)$ & $<0.001^{*}$ \\
\hline * Statistically significant. & & & \\
\hline
\end{tabular}

between the 2 time periods. The most common mechanism of injury was motor vehicle collision (70\%), followed by fall from height (17\%). Among BCVI risk factors, only cervical vertebral body fracture was significantly different post- versus preprotocol $(54 \%$ vs $22 \%$; $p=0.04)$, which may also explain the trend toward more vascular injuries in the vertebral artery territory postprotocol compared with preprotocol ( $75 \%$ vs $48 \% ; \mathrm{p}=0.06)$. Overall, $17 \%$ (8 of 47) of patients with BCVI did not have at least 1 of the screening risk factors, whereas only $7 \%$ (39 of 566) of patients with trauma who had BCVI risk factors were actually diagnosed with BCVI.

Characteristics of the subset of patients diagnosed with BCVI were different from the overall trauma population, being younger in age $(p=0.03)$, predominantly female $(p<0.001)$, and having a more severe injury presentation with a higher ISS $(p<0.001)$ and a lower Glasgow Coma Scale $(\mathrm{GCS})$ score $(\mathrm{p}<0.001)$. There was a trend toward a different distribution of BCVI injury grades after protocol implementation, with an increase in Grade 4 vascular injuries and a decrease in Grades 2 and 3 vascular injuries $(\mathrm{p}=0.07$; Fig. 1).

\section{Stroke Secondary to BCVI}

Overall, there was a trend toward less ischemic stroke observed in patients with BCVI postprotocol compared with preprotocol ( 7 patients vs 13 patients; $p=0.06$; Fig. 2). The corresponding trauma population stroke rates were $0.23 \%$ and $0.53 \%$, respectively, with a $0.3 \%$ absolute risk reduction and 57\% relative risk reduction. Overall, strokes occurred more frequently from carotid artery injuries than from vertebral artery injuries $(60 \%$ vs $31 \% ; \mathrm{p}=0.04)$. The mean number of days from trauma center presentation to development of stroke symptoms was 5.1 days (SD 7.0, median 2, range 0-24 days) and 7.0 days (SD 6.5, median 5 , range 1-19 days) before and after screening protocol implementation, respectively $(\mathrm{p}=0.24)$.

Despite implementation of a BCVI screening protocol, there were still 2 patients who developed potentially preventable ischemic strokes secondary to BCVI, defined as strokes occurring before vascular imaging and more than 2 days after trauma center presentation. A period of 2 days was selected to permit adequate time for most patients with trauma to undergo the CTA screening process, as well as for interpretation and dissemination of radiological results. No patient with a negative CTA was subsequently diagnosed with BCVI or developed stroke symptoms in the hospital.

\section{Management of BCVI}

Overall, $75 \%$ of patients with trauma diagnosed with BCVI were treated with antiplatelet agents (e.g., acetylsalicylic acid [ASA] and/or clopidogrel), with significantly more patients treated postprotocol than preprotocol $(88 \%$ vs $61 \% ; p=0.05$; Table 4 ). However, there were fewer patients treated with intravenous heparin postprotocol $(4 \%$ vs $26 \% ; \mathrm{p}=0.05$ ). The mean time to initiation of medical treatment after BCVI diagnosis was 5.6 (median 0) days and 2.7 (median 0) days preprotocol and postprotocol, respectively $(\mathrm{p}=0.95)$.

No patient experienced new or increasing symptomatic intracerebral hemorrhage after antiplatelet or intravenous heparin therapy for BCVI, despite $70 \%$ of patients with BCVI having evidence of traumatic brain injury on initial imaging. One patient who was started on clopidogrel had a self-limiting upper gastrointestinal bleeding episode that did not require blood transfusion. Two patients (9\%) were treated with endovascular therapy, both during the preprotocol period. Overall, 10 patients $(21 \%)$ did not receive either medical or endovascular treatment. One patient with a right extracranial internal carotid artery dissection developed amaurosis fugax in her right eye despite being on ASA and clopidogrel. She later underwent a carotid stenting procedure.

\section{Clinical Outcomes of Patients With BCVI}

Clinical outcomes at hospital discharge before and after the protocol implementation were not significantly different (Table 4). There was no significant difference in the in-hospital mortality rate between groups $(13 \%$ vs $8 \% ; \mathrm{p}=0.67)$. The mortality rates in stroke and nonstroke patients with BCVI were $20 \%$ and $4 \%$, respectively $(\mathrm{p}=$ $0.15)$. Also, there were no significant differences in intensive care unit LOS or overall hospital LOS.

\section{Discussion}

In our Level 1 trauma center, an institutional, consensus-based CTA screening protocol for BCVI did not appear to increase the rate of BCVI detection. However, there was a trend toward a decreased rate of ischemic stroke secondary to BCVI. For calculation of the stroke 
TABLE 3. Clinical information for patients with trauma diagnosed with BCVI

\begin{tabular}{|c|c|c|c|}
\hline Variable & Preprotocol, 2002-2005 & Postprotocol, 2005-2008 & $\mathrm{p}$ Value \\
\hline Pts w/ BCVI Dx & $23: 2431(0.9 \%)$ & $24: 3049(0.8 \%)$ & 0.53 \\
\hline Mean age, yrs & 34.9 (SD 13.6, range 16-57) & 41.6 (SD 19.1, range 17-78) & 0.18 \\
\hline Sex, F; no. (\%) & $12(52)$ & $16(67)$ & 0.31 \\
\hline Mean ISS & 31.5 (SD 14.1, range 14-66) & 31.0 (SD 13.1, range 13-59) & 0.91 \\
\hline Mean GCS score & 11.2 (SD 5.2, range 3-15) & 10.6 (SD 5.5, range 3-15) & 0.76 \\
\hline Intubated at hospital presentation, no. (\%) & $11(48)$ & $9(38)$ & 0.47 \\
\hline Traumatic brain injury, no. (\%) & $17(74)$ & $16(67)$ & 0.59 \\
\hline \multicolumn{4}{|l|}{ Trauma mechanism, no. (\%) } \\
\hline $\mathrm{MVC} / \mathrm{MBC}$ & $16(70)$ & $17(71)$ & 0.92 \\
\hline Fall from height & $4(17)$ & $4(17)$ & 1.0 \\
\hline Pedestrian/cyclist vs car & $3(13)$ & $2(8)$ & 0.67 \\
\hline Projectile & 0 & $1(4)$ & 1.0 \\
\hline \multicolumn{4}{|l|}{ BCVI risk factors, no. (\%) } \\
\hline Displaced midface & $1(4)$ & $2(8)$ & 1.0 \\
\hline Complex mandibular Fx & $2(9)$ & 0 & 0.23 \\
\hline Closed head injury w/ DAI & $3(13)$ & $5(21)$ & 0.70 \\
\hline Near hanging & 0 & 0 & - \\
\hline Physical signs* & 0 & 0 & - \\
\hline Fx involving carotid canal & $2(9)$ & $4(17)$ & 0.67 \\
\hline Fx involving transverse foramen & $6(26)$ & $7(29)$ & 1.0 \\
\hline Cervical vertebral body Fx & $5(22)$ & $13(54) \dagger$ & $0.036 \ddagger$ \\
\hline C-1 & 1 & 5 & 0.19 \\
\hline $\mathrm{C}-2$ & 1 & 3 & 0.61 \\
\hline C-3 & 0 & 0 & - \\
\hline C-4 & 0 & 1 & 1.0 \\
\hline C-5 & 0 & 4 & 0.11 \\
\hline C-6 & 2 & 3 & 1.0 \\
\hline C-7 & 1 & 0 & 0.49 \\
\hline No positive risk factors, no. (\%) & $6(26)$ & $2(8)$ & 0.14 \\
\hline Multiple risk factors, no. (\%) & $2(9)$ & $10(42)$ & $0.017 \ddagger$ \\
\hline \multicolumn{4}{|l|}{ Vascular imaging } \\
\hline CTA, no. (\%) & $14(61)$ & $23(96)$ & $0.004 \ddagger$ \\
\hline MRA, no. (\%) & $12(52)$ & $1(4)$ & $<0.001 \ddagger$ \\
\hline DSA, no. (\%) & $8(35)$ & $3(13)$ & 0.093 \\
\hline Mean time to first vascular imaging, days & 8.2 (SD 15.1, median 3, range 0-63) & 2.5 (SD 4.1, median 1, range 0-19) & 0.12 \\
\hline \multicolumn{4}{|l|}{ BCVI location, no. (\%) } \\
\hline Carotid artery, total & $12(52)$ & $8(33)$ & 0.19 \\
\hline Extracranial & $10(43)$ & $5(21)$ & 0.13 \\
\hline Intracranial & $2(9)$ & $3(13)$ & 1.0 \\
\hline Vertebral artery, total & $11(48)$ & $18(75)$ & 0.055 \\
\hline Extracranial & $11(48)$ & $16(67)$ & 0.19 \\
\hline Intracranial & 0 & $2(8)$ & 0.49 \\
\hline
\end{tabular}

$\mathrm{Dx}=$ diagnosis; $\mathrm{MBC}=$ motorbike crash; $\mathrm{MVC}=$ motor vehicle crash; $-=\mathrm{p}$ value is undefined.

* Physical signs include seat-belt sign and neck swelling.

$\dagger$ Three patients had spine fractures at 2 cervical levels.

$\ddagger$ Statistically significant.

rates and statistical comparisons, we used the total trauma population as the denominator rather than the total number of patients diagnosed with BCVI. A stroke rate based on the total number of patients with BCVI may be mislead- ing, because a CTA screening protocol may detect BCVI with a possibly more benign clinical course. This study provides additional support for the importance of having formalized BCVI screening protocols at trauma centers. 


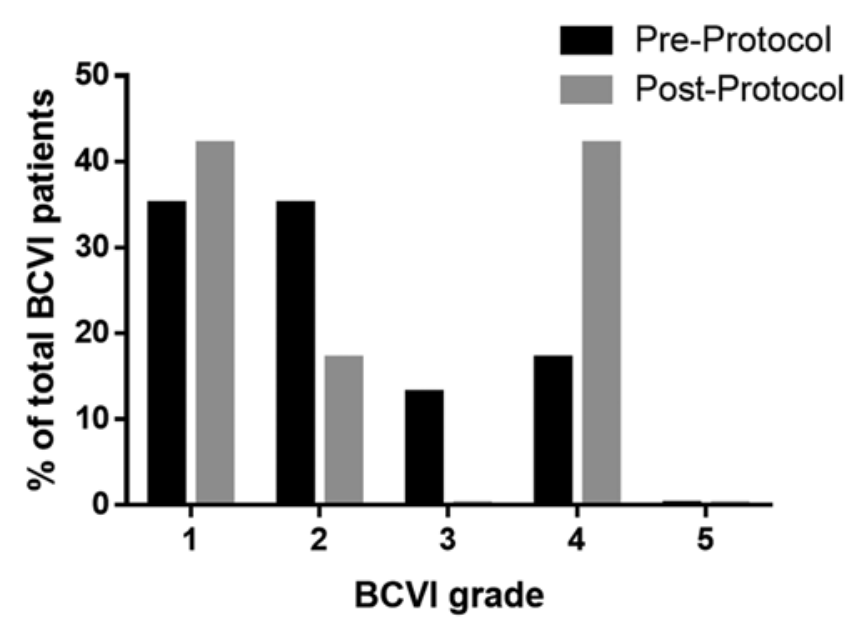

FIG. 1. Grading of BCVI in patients with trauma before and after implementation of a CTA screening protocol.

We believe that the observed decreased stroke rate may have been due to the increased screening and earlier diagnosis of BCVI with a CTA screening protocol in place. However, it is important to recognize that there were several differences between the 2 compared periods that may have influenced the rate of ischemic complications. The overall baseline clinical characteristics of the trauma population before and after the screening protocol were similar, except for patients being slightly older and less likely to be intubated at hospital presentation during the postprotocol period. If anything, a clinical cohort of older patients would have led to a higher stroke rate.

The decreased likelihood of intubation may be related to changes in practice patterns rather than being an indicator of less severe trauma, because the presenting GCS scores and ISSs were similar between the 2 compared time periods. Also, among the patients with trauma diagnosed with BCVI, there were significantly more patients with cervical vertebral body fractures, leading to a trend toward more vertebral artery injuries during the postprotocol period. Vertebral artery injuries may have a lower stroke risk than carotid artery injuries, although this finding is not consistent across all studies.19,20,25-28 There were more Grade 4 injuries, but fewer Grade 2 or 3 injuries during the postprotocol period. It is known that higher-grade vascular injuries have an increased stroke rate compared with lower-grade injuries; thus, we would have expected a higher stroke rate postprotocol based on BCVI grade distribution alone. ${ }^{4,25-28}$

Also, the channel number of the CT scanners increased during the years of the study, with a 4-channel multidetector CT scanner used preprotocol and a 64-channel multidetector CT scanner predominantly used postprotocol. In a meta-analysis, Roberts et al. reported a higher BCVI sensitivity in CT scanners with greater numbers of channels. ${ }^{22}$ Finally, there were more patients with BCVI receiving antiplatelet treatment or anticoagulation during the postprotocol period, which may have led to the decreased stroke rate. A greater awareness of BCVI and its ischemic complications may have led to an increased propensity to treat the vascular injuries.

Three groups have published clinical studies concerning the effect of a CTA-based BCVI screening protocol on stroke rates. ${ }^{14,23,24}$ Investigators from the University of British Columbia found a decrease in stroke rate from $67 \%$ prior to the CTA screening protocol (1992-2000) to 0\% with the CTA screening protocol (2002-2003). ${ }^{17,18,24}$ However, the comparison groups were not based on consecutive years, and the $0 \%$ stroke rate omitted 1 patient with trauma who was diagnosed with a stroke but failed to undergo CTA screening despite the presence of BCVI risk factors. ${ }^{24}$ Similarly, with a CTA screening protocol, Rogers et al. also found a decrease in the number of strokes postprotocol, but overall stroke rates were low. ${ }^{23}$ After transitioning from a DSA-based screening protocol to a CTA-based screening

\section{Patients with ischemic - stroke secondary to BCVI $(p=0.06)$}

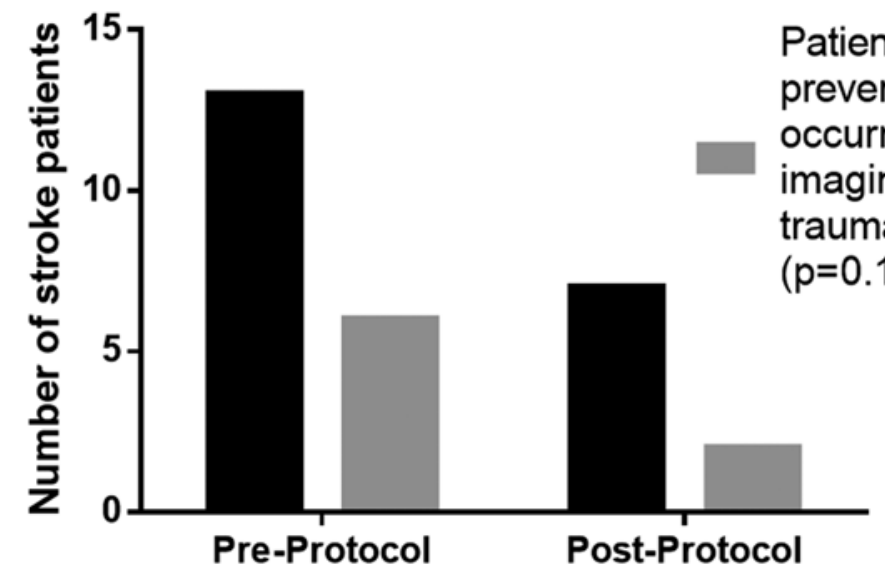

FIG. 2. Number of patients with trauma who had BCVI who developed ischemic stroke before and after implementation of a CTA screening protocol. There was a trend toward a reduction in ischemic stroke after implementation of the protocol $(0.23 \%$ vs $0.53 \%$; $p=0.06)$. 
TABLE 4. Management and clinical outcomes of patients with trauma diagnosed with BCVI

\begin{tabular}{|c|c|c|c|}
\hline Variable & Preprotocol, 2002-2005, $n=23$ & Postprotocol, 2005-2008, n = 24 & p Value \\
\hline \multicolumn{4}{|l|}{ Medical Tx } \\
\hline Any antiplatelet agent & $14(61)$ & $21(88)$ & $0.049^{*}$ \\
\hline ASA & $13(57)$ & $20(83)$ & 0.12 \\
\hline Clopidogrel & $4(17)$ & $3(13)$ & 0.70 \\
\hline ASA + clopidogrel & $3(13)$ & $2(8)$ & 0.67 \\
\hline Intravenous heparin & $6(26)$ & $1(4)$ & $0.048^{*}$ \\
\hline Mean time to medical Tx after BCVI Dx, days & 5.6 (SD 16.6, median 0, range 0-63) & 2.7 (SD 4.5, median 0, range $0-17$ ) & 0.95 \\
\hline Endovascular Tx, no. (\%) & $2(9)$ & 0 & 0.23 \\
\hline Mortality, no. (\%) & $3(13)$ & $2(8)$ & 0.67 \\
\hline Mean mRS score at hospital discharge & 2.9 (SD 1.9, range 1-6) & 2.9 (SD 1.9, range 0-6) & 0.63 \\
\hline Hospital LOS, days & 33.2 (SD 40.0, range 2-190) & 34.5 (SD 28.7, range 3-99) & 0.90 \\
\hline ICU LOS, days & 11.9 (SD 17.7, range 0-70) & 9.0 (SD 9.2, range 0-27) & 0.49 \\
\hline
\end{tabular}

$\mathrm{Tx}=$ treatment.

* Statistically significant.

protocol for BCVI, Eastman et al. reported a significant decrease in stroke rates, from $15.2 \%$ to $3.8 \% .^{14}$

Foothills Medical Centre is the sole Level 1 trauma center for a large geographic region and sizable population. This makes it ideal for epidemiological studies, especially those looking at clinical conditions that have a relatively low prevalence, such as BCVI in the trauma population. The detection of BCVI with CTA in this trauma population remained unchanged after implementation of the screening protocol, with an overall prevalence of $0.9 \%$, which is consistent with the prevalence of $0.1 \%-2.7 \%$ in the published literature.? This finding was unexpected; we anticipated that more vascular injuries would be diagnosed during the postprotocol period due to the presence of a screening protocol and the presumed benefit of newer-generation multidetector CT scanners. Screening protocols that are based on CTA have been shown to increase BCVI prevalence in the blunt trauma population from $0.17 \%$ to $1.4 \% .{ }^{24}$ Retrospective studies have found that the radiologists' reading of CTA scans has improved with experience. ${ }^{16}$

As imaging technology continues to evolve, BCVI detection may become more and more sensitive and specific. Because CTA was used as a first-line screening modality in our study, it is probable that vascular injuries were missed that would otherwise have been detected with DSA. However, we did not see an increase in BCVI-related complications. Perhaps the vascular injuries not detected by CTA that would otherwise have been detected by DSA have a milder clinical course. Our use of DSA was primarily to clarify equivocal CTA findings. We have moved away from using MRA due to its poor sensitivity for BCVI detection. ${ }^{3}$ Critics may say that our CTA screening protocol is not inclusive enough, e.g., screening patients with cervical fractures involving the vertebral body and/or extending into the transverse foramen, but not screening patients with isolated laminar or spinous process fractures. As suggested by Burlew and colleagues, at some point there needs to be a level of cost-consciousness in an environment where resources are limited. ${ }^{8}$ There will be patients with BCVI who do not have any identifiable risk factors (17\% in our study). To detect all patients with BCVI, one study estimated that $96 \%$ of the blunt trauma population would need to be screened, which is not practical for most institutions. ${ }^{9}$

Our management philosophy is similar to previously published guidelines, which state that medical management is the first-line treatment for BCVI, assuming no absolute contraindications, and endovascular treatment is avoided if possible. ${ }^{1}$ The majority of the patients with BCVI in our study were treated with medical therapy. Patients with BCVI commonly also have traumatic brain injury (70\% in our study). The decision to initiate treatment for BCVI requires consensus among our neurosurgery, stroke neurology, radiology, trauma surgery, and critical care teams, with a thoughtful consideration of the bleeding risks associated with antiplatelet agents and/or anticoagulation balanced with the potential morbidity of ischemic complications.

Cothren and colleagues identified a 2.8\% (8 of $282 \mathrm{BC}$ VIs) significant bleeding complication rate after initiating medical therapy in patients with asymptomatic BCVI. ${ }^{10}$ One concern with using an antiplatelet agent is that its reversibility in the setting of life-threatening hemorrhage is more difficult than with intravenous heparin. We have found treatment with ASA to be safe, with no patient in our study developing new or progressive symptomatic intracerebral hemorrhage. The study by Cothren et al. found that the choice of medical therapy for BCVI, either heparin or antithrombotic therapy, did not affect the stroke rate or the vascular wall healing rate..$^{10}$ Another report by Cothren et al. reported significant risks with endovascular intervention in patients with BCVI. ${ }^{11}$ However, DiCocco et al. demonstrated good outcomes after endovascular therapy in a large case series of patients with BCVI. ${ }^{13}$

There are several important limitations to this study. First, this study is a retrospective analysis. Also, the Alberta Trauma Registry only includes patients with trauma who have an ISS $>12$, possibly excluding a small number of patients with BCVI who have a lower overall injury severity. The registry also includes all types of trauma, not only blunt trauma. In addition, the neuroradiologistreported BCVI-negative vascular imaging studies were 
not reanalyzed, possibly leading to missed BCVI injuries. Confirmatory DSA studies were not routinely performed to check abnormalities found on CTA. Most patients with BCVI were not followed up as outpatients; thus, strokes secondary to BCVI after hospital discharge may have been missed. Initiation, type, and duration of treatments were individualized and were at the discretion of the trauma team and consulting services.

\section{Conclusions}

Guidelines published by major trauma associations have advocated for the need for BCVI screening protocols at trauma centers. ${ }^{1,7}$ In keeping with these guidelines, this study provides additional support that the implementation of a formalized BCVI screening protocol with CTA in a Level 1 trauma center may be of clinical benefit, with a trend toward a reduction in ischemic complications. Although more patients underwent BCVI screening postprotocol, there is still room for improvement in terms of reducing the number of missed screenings. It is important for such a protocol to have the support of all clinical specialties involved in managing traumatic neurovascular injuries, including trauma surgery, neurosurgery, critical care, stroke neurology, diagnostic radiology, and interventional neuroradiology. The BCVI screening criteria continue to evolve, emphasizing the need to periodically update institutional screening protocols. Treatment of BCVI with antiplatelet agents appears to be safe. Multicenter, prospective registries would help to determine how best to manage patients with BCVI to prevent stroke sequelae.

\section{Acknowledgments}

We acknowledge the input provided by Dr. Parviz Dolati. Data for this study were provided by the Alberta Trauma Registry.

\section{References}

1. Biffl WL, Cothren CC, Moore EE, Kozar R, Cocanour C, Davis JW, et al: Western Trauma Association critical decisions in trauma: screening for and treatment of blunt cerebrovascular injuries. J Trauma 67:1150-1153, 2009

2. Biffl WL, Egglin T, Benedetto B, Gibbs F, Cioffi WG: Sixteen-slice computed tomographic angiography is a reliable noninvasive screening test for clinically significant blunt cerebrovascular injuries. J Trauma 60:745-752, 2006

3. Biffl WL, Moore EE: Computed tomographic angiography for blunt cerebrovascular injuries: don't throw out the baby with the bathwater. Ann Surg 253:451-452, 2011

4. Biffl WL, Moore EE, Offner PJ, Brega KE, Franciose RJ, Burch JM: Blunt carotid arterial injuries: implications of a new grading scale. J Trauma 47:845-853, 1999

5. Biffl WL, Moore EE, Offner PJ, Brega KE, Franciose RJ, Elliott JP, et al: Optimizing screening for blunt cerebrovascular injuries. Am J Surg 178:517-522, 1999

6. Biffl WL, Ray CE Jr, Moore EE, Franciose RJ, Aly S, Heyrosa MG, et al: Treatment-related outcomes from blunt cerebrovascular injuries: importance of routine follow-up arteriography. Ann Surg 235:699-707, 2002

7. Bromberg WJ, Collier BC, Diebel LN, Dwyer KM, Holevar MR, Jacobs DG, et al: Blunt cerebrovascular injury practice management guidelines: the Eastern Association for the Surgery of Trauma. J Trauma 68:471-477, 2010

8. Burlew CC, Biffl WL, Moore EE, Barnett CC, Johnson JL, Bensard DD: Blunt cerebrovascular injuries: redefin- ing screening criteria in the era of noninvasive diagnosis. $\mathbf{J}$ Trauma Acute Care Surg 72:330-337, 539, 2012

9. Cook A, Osler T, Gaudet M, Berne J, Norwood S: Blunt cerebrovascular injury is poorly predicted by modeling with other injuries: analysis of NTDB data. J Trauma 71:114-119, 2011

10. Cothren CC, Biffl WL, Moore EE, Kashuk JL, Johnson JL: Treatment for blunt cerebrovascular injuries: equivalence of anticoagulation and antiplatelet agents. Arch Surg 144:685690, 2009

11. Cothren CC, Moore EE, Ray CE Jr, Ciesla DJ, Johnson JL, Moore JB, et al: Carotid artery stents for blunt cerebrovascular injury: risks exceed benefits. Arch Surg 140:480-486, 2005

12. DiCocco JM, Emmett KP, Fabian TC, Zarzaur BL, Williams JS, Croce MA: Blunt cerebrovascular injury screening with 32-channel multidetector computed tomography: more slices still don't cut it. Ann Surg 253:444-450, 2011

13. DiCocco JM, Fabian TC, Emmett KP, Magnotti LJ, Zarzaur BL, Bate BG, et al: Optimal outcomes for patients with blunt cerebrovascular injury (BCVI): tailoring treatment to the lesion. J Am Coll Surg 212:549-559, 2011

14. Eastman AL, Muraliraj V, Sperry JL, Minei JP: CTA-based screening reduces time to diagnosis and stroke rate in blunt cervical vascular injury. J Trauma 67:551-556, 2009

15. Fabian TC, Patton JH Jr, Croce MA, Minard G, Kudsk KA, Pritchard FE: Blunt carotid injury. Importance of early diagnosis and anticoagulant therapy. Ann Surg 223:513-525, 1996

16. Malhotra AK, Camacho M, Ivatury RR, Davis IC, Komorowski DJ, Leung DA, et al: Computed tomographic angiography for the diagnosis of blunt carotid/vertebral artery injury: a note of caution. Ann Surg 246:632-643, 2007

17. McKevitt EC, Kirkpatrick AW, Vertesi L, Granger R, Simons RK: Blunt vascular neck injuries: diagnosis and outcomes of extracranial vessel injury. J Trauma 53:472-476, 2002

18. McKevitt EC, Kirkpatrick AW, Vertesi L, Granger R, Simons $\mathrm{RK}$ : Identifying patients at risk for intracranial and extracranial blunt carotid injuries. Am J Surg 183:566-570, 2002

19. Miller PR, Fabian TC, Bee TK, Timmons S, Chamsuddin A, Finkle R, et al: Blunt cerebrovascular injuries: diagnosis and treatment. J Trauma 51:279-286, 2001

20. Miller PR, Fabian TC, Croce MA, Cagiannos C, Williams JS, Vang M, et al: Prospective screening for blunt cerebrovascular injuries: analysis of diagnostic modalities and outcomes. Ann Surg 236:386-395, 2002

21. O'Kelly CJ: Can screening prevent poor outcomes following blunt cerebrovascular injury? Can J Neurol Sci 37:549-550, 2010

22. Roberts DJ, Chaubey VP, Zygun DA, Lorenzetti D, Faris PD, Ball CG, et al: Diagnostic accuracy of computed tomographic angiography for blunt cerebrovascular injury detection in trauma patients: a systematic review and meta-analysis. Ann Surg 257:621-632, 2013

23. Rogers FB, Baker EF, Osler TM, Shackford SR, Wald SL, Vieco P: Computed tomographic angiography as a screening modality for blunt cervical arterial injuries: preliminary results. J Trauma 46:380-385, 1999

24. Schneidereit NP, Simons R, Nicolaou S, Graeb D, Brown DR, Kirkpatrick A, et al: Utility of screening for blunt vascular neck injuries with computed tomographic angiography. J Trauma 60:209-216, 2006

25. Scott WW, Sharp S, Figueroa SA, Eastman AL, Hatchette $\mathrm{CV}$, Madden CJ, et al: Clinical and radiographic outcomes following traumatic Grade 1 and 2 carotid artery injuries: a 10-year retrospective analysis from a Level I trauma center. The Parkland Carotid and Vertebral Artery Injury Survey. J Neurosurg 122:1196-1201, 2015

26. Scott WW, Sharp S, Figueroa SA, Eastman AL, Hatchette $\mathrm{CV}$, Madden CJ, et al: Clinical and radiographic outcomes 
following traumatic Grade 3 and 4 carotid artery injuries: a 10-year retrospective analysis from a Level 1 trauma center. The Parkland Carotid and Vertebral Artery Injury Survey. J Neurosurg 122:610-615, 2015

27. Scott WW, Sharp S, Figueroa SA, Eastman AL, Hatchette $\mathrm{CV}$, Madden CJ, et al: Clinical and radiological outcomes following traumatic Grade 3 and 4 vertebral artery injuries: a 10-year retrospective analysis from a Level I trauma center. The Parkland Carotid and Vertebral Artery Injury Survey. J Neurosurg 122:1202-1207, 2015

28. Scott WW, Sharp S, Figueroa SA, Madden CJ, Rickert KL: Clinical and radiological outcomes following traumatic Grade 1 and 2 vertebral artery injuries: a 10-year retrospective analysis from a Level 1 trauma center. J Neurosurg 121:450-456, 2014

\section{Disclosures}

This study obtained funding from the Calgary Surgical Research Development Fund. This study received the Synthes Craniofacial Award at the 2012 American Association of Neurological Surgeons Annual Scientific Meeting. Dr. Kirkpatrick is the principal investigator of a randomized controlled trial funded by Kinetic Concepts, Inc., and has received travel compensation to Cadaver Labs from Synthes, Inc., and Life Cell Corporation. Dr. Kirkpatrick received non-study-related clinical or research sup- port from Acelity Corporation and is a consultant for Innovative Trauma Care Corporation.

\section{Author Contributions}

Conception and design: Wong, Tso, Kirkpatrick. Acquisition of data: Tso, Lee. Analysis and interpretation of data: Wong, Tso, Ball, Morrish, Mitha, Kirkpatrick. Drafting the article: Tso. Critically revising the article: Wong, Tso, Ball, Morrish, Mitha, Kirkpatrick. Reviewed submitted version of manuscript: all authors. Approved the final version of the manuscript on behalf of all authors: Wong. Statistical analysis: Tso. Study supervision: Wong, Kirkpatrick.

\section{Supplemental Information Previous Presentations}

This paper was presented at the American Association of Neurological Surgeons (AANS) Annual Scientific Meeting in Miami, Florida, April 14-18, 2012, and at the Canadian Neurological Sciences Federation (CNSF) Annual Congress in Ottawa, Canada, June 6-8, 2012.

\section{Correspondence}

John H. Wong, Division of Neurosurgery, Department of Clinical Neurosciences, Hotchkiss Brain Institute, University of Calgary, 140329 St. NW, Foothills Medical Centre, Calgary, AB T2N 2T9, Canada. email: jwong@ucalgary.ca. 